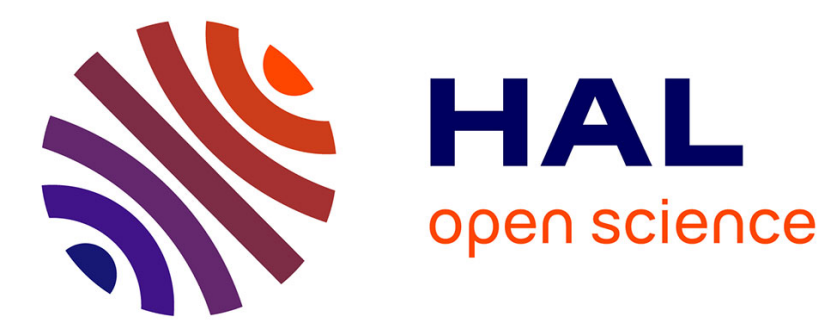

\title{
Smartwalk: Computer Science on the Schoolyard
}

Michael Weigend

\section{To cite this version:}

Michael Weigend. Smartwalk: Computer Science on the Schoolyard. 11th IFIP World Conference on Computers in Education (WCCE), Jul 2017, Dublin, Ireland. pp.525-535, 10.1007/978-3-319-743103_53. hal-01762864

\section{HAL Id: hal-01762864 https://hal.inria.fr/hal-01762864}

Submitted on 10 Apr 2018

HAL is a multi-disciplinary open access archive for the deposit and dissemination of scientific research documents, whether they are published or not. The documents may come from teaching and research institutions in France or abroad, or from public or private research centers.
L'archive ouverte pluridisciplinaire HAL, est destinée au dépôt et à la diffusion de documents scientifiques de niveau recherche, publiés ou non, émanant des établissements d'enseignement et de recherche français ou étrangers, des laboratoires publics ou privés. 


\title{
Smartwalk: Computer Science on the Schoolyard
}

\author{
Michael Weigend \\ Holzkamp Gesamtschule Witten, Germany \\ mw@creative-informatics.de
}

\begin{abstract}
Smartwalk is a playful enrichment activity for sixth- or seventhgraders on computer science. It takes place outside on the schoolyard. The basic idea is to do things that Generation Z-kids usually do with their mobile devices in a different (metaphorical) way using the physical environment outside on the schoolyard. The goal is to make aware of computer sciences concepts adopted in smartphone apps and to promote the acquisition of computational thinking.
\end{abstract}

Keywords. Computational thinking, mobile device, computer science concepts, media education

\section{Media Education and Computer Science}

In many western countries, high school students - the Generation Z - are comfortable with digital technology from young age. For example, $83 \%$ of German children in the age of 12 to 13 own a smartphone with internet connectivity and most of them are members of social networks [1]. However, there is some scepticism among parents and teachers regarding the proper use of digital devices. Based on the results of his study on 300.000 smartphone users, Alexander Markowetz warns that we are in danger of a "digital burnout" [2]. Especially young people get interrupted too often by a ringing cell phone. This leads to a loss of joy and productivity. Frequent use of digital technology does not necessarily imply information literacy. This is why there is a tendency at schools to include media education in the curriculum. Media skills are taught either within a dedicated subject (like computer science) or elements of media education are distributed on several traditional subjects: image processing in art lessons, data visualization in mathematics lessons, presentations in Science lessons etc. The Smartwalk actvity is considered to be a "stand alone" element of media education, which does not require any specific pre-knowledge and can therefore be allocated to any subject. It is designed for a certain environment - the schoolyard of some German high school - but it can easily be adapted to any schoolyard. In contrast to activities practicing the efficient and responsible usage of digital technology (media literacy), Smartwalk focuses on the computer science background. There are basically two main goals:

1) The participants get an idea of computer science concepts that are adopted in software on mobile devices.

2) They develop computational thinking.

The basic idea of Smartwalk is to do things that Generation Z-kids usually do with their mobile devices in a different (metaphorical) way outside in fresh air. For 
example they publish a statement similar to a SnapChat posting by putting a sticky note to a wall. They create "Land Art" artifacts somewhere on the schoolyard and make them accessible to the public by publishing the title and a URL-like address. Other topics covered by Smartwalk are augmented reality (adopted for example in Pokémon Go), image recognition and navigation.

Smartwalk takes two lessons (90 minutes). The class (grade 6 or 7, ages 11 to 13) is divided in small "mission teams" of four persons. Each team gets a mission plan containing directions where to go and challenges that have to be solved at certain locations. Some of the locations are specified by a photo and/or coordinates on a map and thus easy to find. The teams can start at different entry points and then follow a common path. They try to solve as many tasks as possible during the given time. At the end there are at least ten minutes of evaluation and reflection.

\section{Task Design}

Smartwalk is a computer science activity without computers. For this Bell, Witten and Fellows have coined the term "computer science unplugged" and meanwhile there are several collections of "unplugged" activities illustrating computer science concepts $[3,4,5]$. Especially to mention is the big reservoir of quiz tasks provided by the Bebras International Challenge on Informatics and Computational Thinking (http://www.bebras.org). One rule for the design of a Bebras task is that it must contain all information necessary to solve it. Another rule is that it must be solvable in two or three minutes. Smartwalk challenges are similar to Bebras tasks. The main difference is that they are intensely connected to the real life environment. Part of the information, which is necessary for solving a task, is not just given but must be found by interacting with the physical environment. The children walk around, get exhausted, observe carefully and co-operate with class mates. Smartwalk has elements of an experience-oriented setting. The idea is to make it more exciting for children. One has to consider that activities related to computational thinking may not sound very interesting to young people. For example, according to the ROSE study (Relevance of Science Education) "searching for structure" seems to be one of most boring item for fifteen years old students in Germany and other European countries [6]. Aversions of this kind are barriers that have to be overcome, when it is about motivating young people to go into informatics. Kurt Hahn, the inventor of the "outward bound" movement, argues that only in unusual and somewhat adventurous situations people are open to try new ways of thinking and acting [7].

\section{Fostering computational thinking}

As Jeanette Wing defines in 2006, "computational thinking represents a universally applicable attitude and skill set everyone, not just computer scientists, would be eager to learn and use" [8, p. 33]. Based on an analysis of relevant literature, Selby and Woollard identify five basic facets of computational thinking: Abstraction, decomposition, evaluation, algorithmic thinking and generalization [9]. This section 
presents a few tasks from the Smartwalk activity illustrating how to foster some of these skills in an outdoor setting.

\subsection{Abstraction}

Computer programming includes abstraction. The programmer considers only those aspects of a phenomenon which are relevant for the purpose of the project and ignores unimportant details (from Latin abstrahere "to drag away"). In computer science the usage of metaphors and formal languages are two means of abstraction. [10] suggest that a metaphorical term is a prototype of a category. Therefore the metaphorical meaning is more abstract than the literal meaning. Based on this idea they define levels of abstraction. The more abstract an expression the more facets of the literal meaning are missing in the metaphoric meaning. Psycholinguists define metaphorical thinking as a transfer of knowledge from a familiar source domain to target domain. Conceptual metaphors are "vehicles" carrying the learners to new knowledge beyond their intellectual horizons [11]. In programming, conceptual metaphors are used on several levels of abstraction. Well known high level metaphors are "World Wide Web" or the "scan line" in algorithmic geometry. Data structures or standard classes like stacks and queues are metaphors projecting knowledge about physical collections onto the domain of data processing. For example, a physical stack of plates supports certain access-operations: You can only remove the top plate (pop) and put a new plate on top of the stack (push).

In the following task a metaphor is used to define a structure consisting of one object in the middle and several objects of a different type around it.

Challenge 7: Find a thing, which is similar to the image.

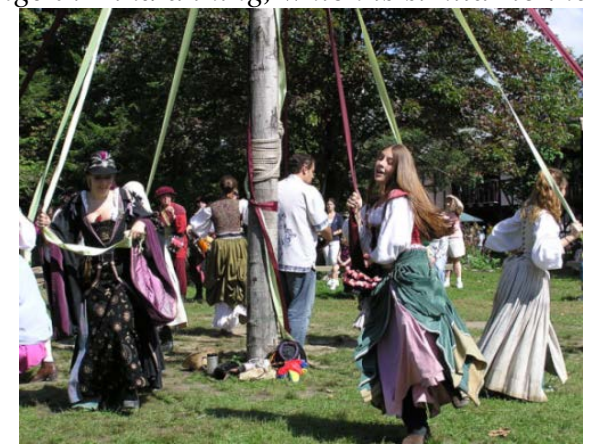

Fig. 1: Dancing around a maypole at a Renaissance faire in Tuxedo Park (photo: public domain)

The image on the left hand side of figure 2 depicts the expected solution. But a manhole cover, (which actually exists at a different location on the schoolyard) also corresponds to the maypole dancing. 

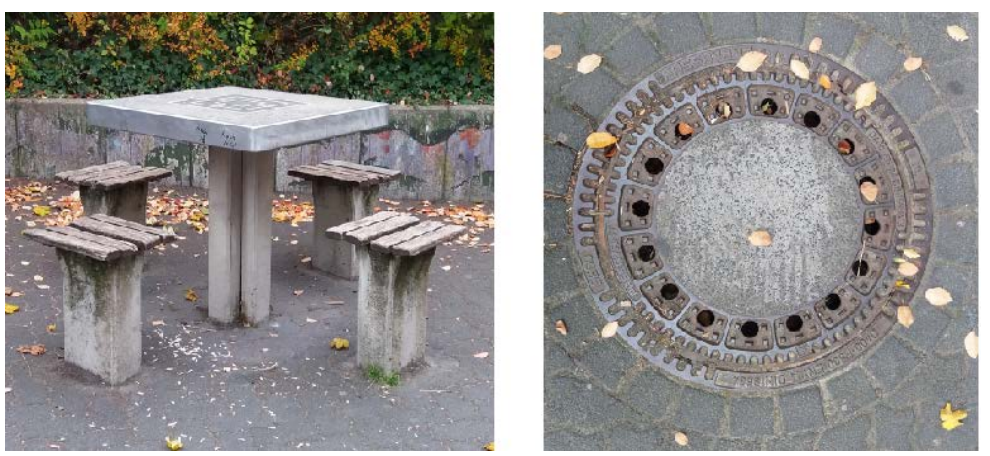

Fig. 2. Two different objects corresponding to the same metaphor

Another technique of abstraction in computer programming obviously is the use of a formal language for describing structures. The following task uses the Python notation of tuples to describe a sequence of objects:

Challenge 3: At the wall there are several objects with the structure $(0,1,0,0,1,0)$. What is the purpose of these objects?

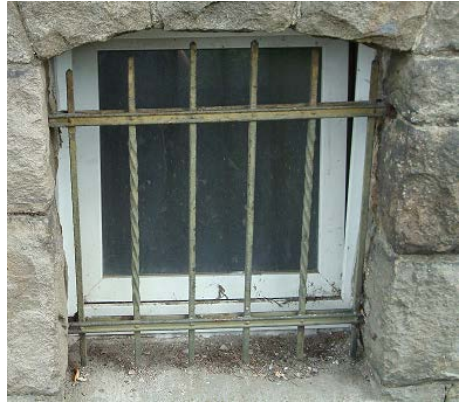

Fig. 3. A window protection with two types of bars

The expected solution is shown in figure 3 . The tuple is an abstraction of a window protection consisting of two different types of bars. The number 0 represents a straight bar and the number 1 represents a twisted bar.

\subsection{Algorithms}

An algorithm is a precise description of activity that leads to a certain goal. Every computer program is an algorithm. Creating and understanding algorithms is one of the core competences of computer scientist. The Smartwalk mission plan contains directions to certain places on the schoolyard. These are algorithms, mostly consisting of linear sequences of commands like "walk 50 steps straight on". They may also contain control structures with complex conditions like "Walk along the wall until you are standing beside two vertical wires." Algorithms can also be used to identify a static structure, as in the following task.

Challenge 8: Look around and find a thing, which has been constructed this way: 
go forward $200 \mathrm{~cm}$

repeat 4 times:

turn right $30^{\circ}$

go forward $30 \mathrm{~cm}$

Figure 4 depicts the solution.

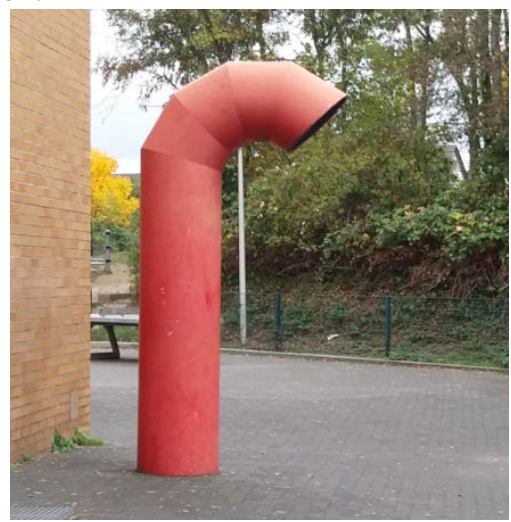

Fig. 4. Air ventilation pipe

Algorithms are an integral part of software that children use in their everyday life. The behaviour of a product as well as the ways how to use it is defined by algorithms. For example, a SnapChat message is not just a media but it has some kind of behaviour that is defined by an algorithm. It vanishes after some time. In challenge 11 the Smartwalkers create postings with a lifetime.

- $\quad$ Find the wall depicted on the photo.

- Write a poem (two lines) on a sticky note and put it at the left side of the "Postings"-area.

- $\quad$ Read two or three postings that are already sticking at the wall. After you have read a posting move it for one step to the right.

- Remove the postings that have left the "Postings"-area.

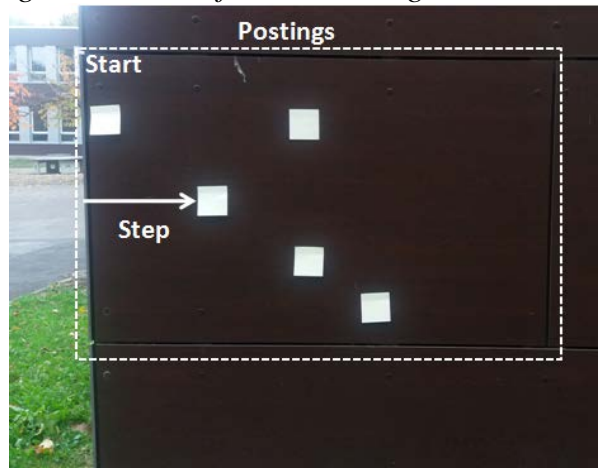

Fig.5. A wall for posting poems 


\subsection{Decomposition}

In the context of computer programming the term decomposition means breaking down a large problem into smaller chunks that are easier to handle. Like abstraction, decomposition is a means to cope with complexity. In object oriented programming decomposition takes place during the design of a system, when the developer creates a class diagram representing the whole project. The following tasks are simple examples of decomposition in everyday life.

Challenge 6: Look around. There is a thing with this structure:

((plastic, plastic, plastic), (metal, metal))

Figure 6 shows the solution.

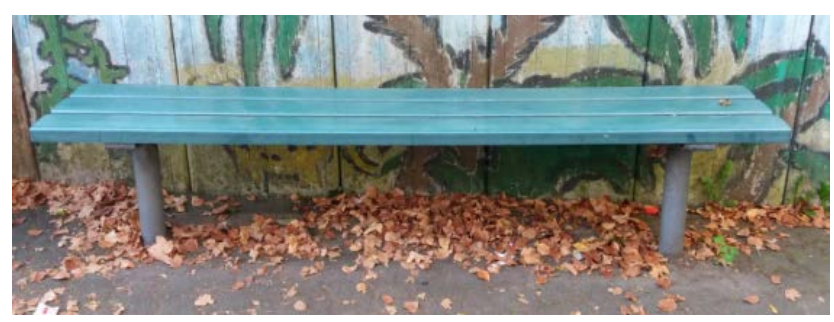

Fig. 6. A bench on the schoolyard

The following task is more abstract since it does not use meaningful names. On the other hand it is more explicit because it introduces names for the parts of the whole aggregate.

Challenge 5: Follow the way and look down.

Find something that has structure B, which is described in the box.
$A=(a, a, a, a, a, a, a)$
$B=(A, A)$

Draw an $a$.

Figure 7 shows the object that is expected to be found: a drain. The model is a nested tuple. Object B is a tuple containing two objects A, which consist of seven objects a each. Thus, the Smartwalkers are expected to draw an elongated hole.

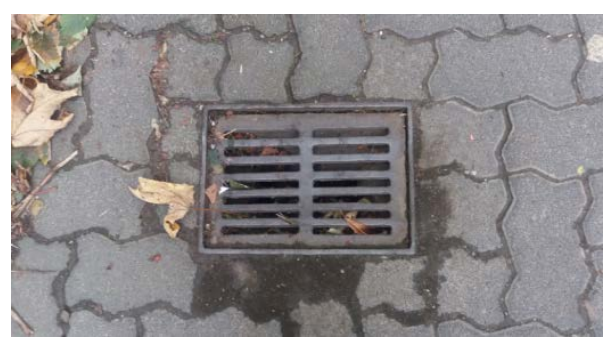

Fig. 7. A drain on the ground 


\subsection{Generalisation}

Generalisation means to deduce a general principle from examples. In the following challenge generalisation is adopted to figure out the addressing technique.

Challenge 9: Some areas on the schoolyard have identifiers that are explained in the satellite photo. In the area with the identifier science. 1 there is a small tree.

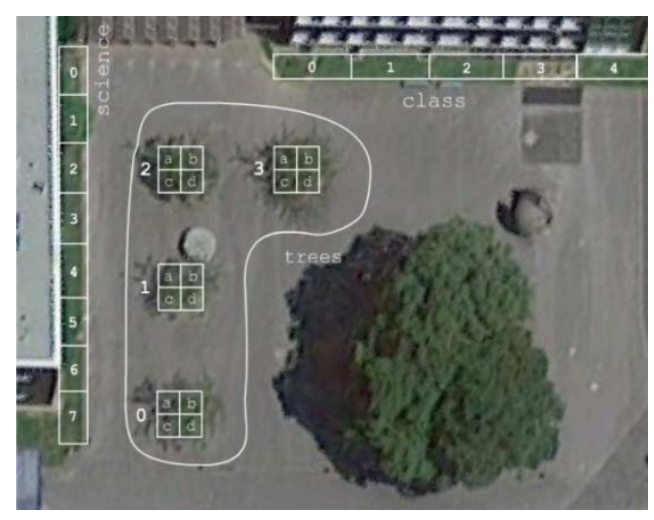

Fig. 8: URL-like Addresses of areas on a schoolyard

a) What kind of sports equipment is close to area trees.1.b? b) Tell the identifier of the area, where there is a manhole cover (photo).

Note that understanding the given example and solving the tasks requires exploring the physical environment and finding the mentioned objects (small tree, sports equipment, manhole cover).

\section{Evaluation}

Smartwalk was performed with 48 students (age 11 to 13 from grades 6 and 7) at a German high school in autumn 2016 (24 girls, 14 boys, 10 did not tell their gender). Each four-persons mission team was accompanied by a tutor. These were students from a pedagogy class (age 18 to 20), who already had some experience with similar enrichment activities [12]. They had solved all tasks before, and had discussed the underlying CS concepts. Some of the tasks were considered to be rather difficult. So the pedagogy students developed scaffolding hints that do not reveal the solution (according to the Montessori motto "Help me to do it myself").

At the end of the mission the tutors asked the younger students to rate the tasks. They sat together and discussed in what way the challenges were connected to computer science. As a start a tutor presented some concepts or digital techniques and asked the young participants to allocate corresponding challenges. Example:

"The digital camera in your smartphone can recognize faces on an image. The camera app explores the shapes in the image and when it finds a certain pattern, it draws a rectangle or circle around it which you can see on the display. A simple 
pattern of a human face is a smiley consisting of two dark spots (the eyes) and a curved line below (the mouth). This is just an example. Many computer programs use simple patterns of real things. Which challenges were about recognizing a pattern?”

Table 1 shows some results. It displays for each challenge the average ratings and the percentage of students, who considered this challenge to be related to a certain concept or technology:

- CT: Computer technology in general

- A: Addresses like URLs in the WWW

- AR: Augmented Reality like in Pokémon Go

- Nav: Navigation like in guiding systems

- Pat: Recognizing patterns like the pattern of a face, which is recognized by camera software

- Sna: Publishing images like in SnapChat

For each concept or technology the students could mark at most three corresponding challenges. The students rated the attractiveness of a challenge (item Attract) by numbers from 1 (very good) to 6 (very poor). The item Success indicates how well the participants solved a task. The value is the average of group tutors' ratings (percentage of maximum points). A "mission team" could earn between 0 and 3 points for a challenge, depending on how much help they got from their tutor.

Table 1. Students' ratings of Smartwalk challenge $(n=48$, average age 11.9 years)

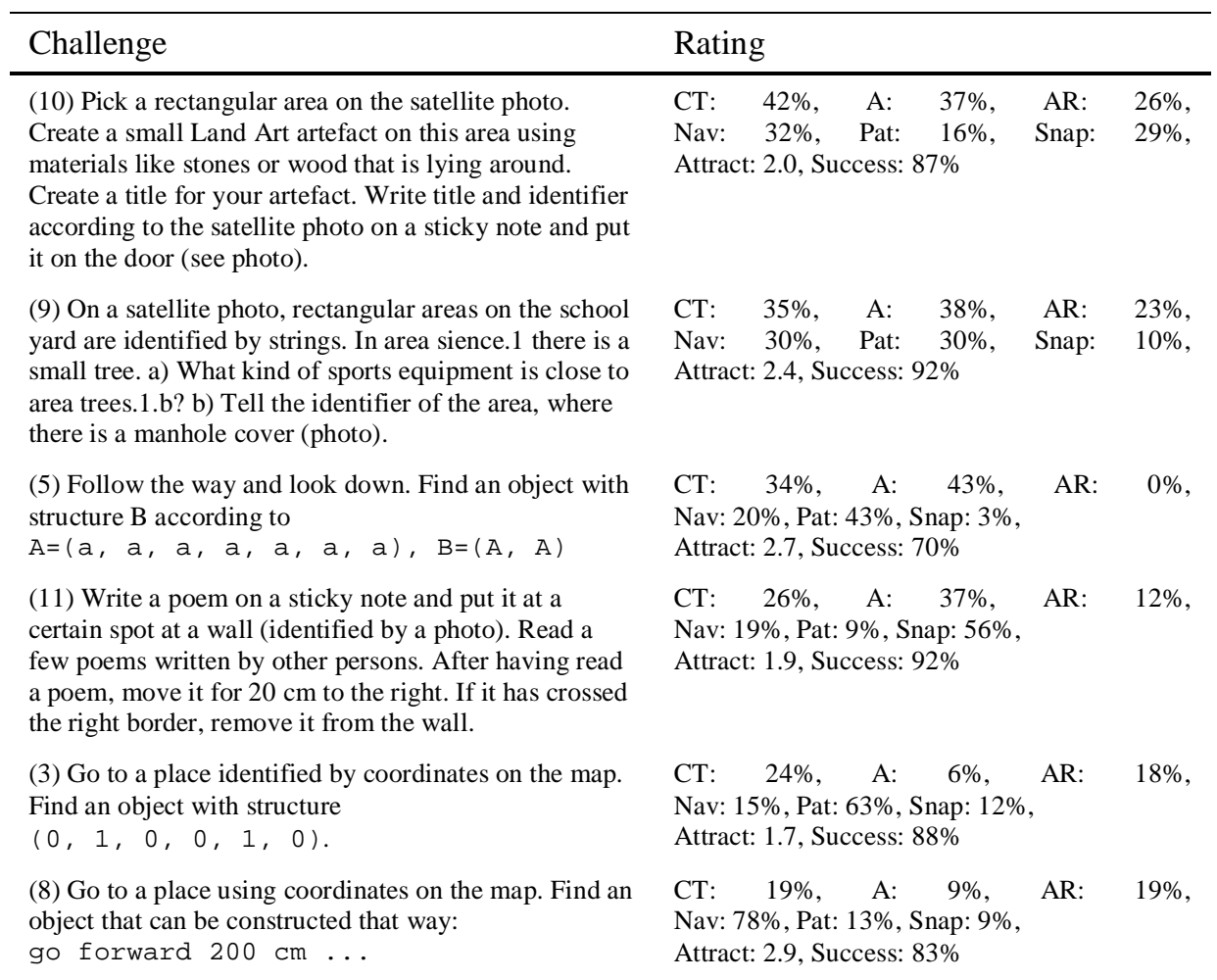


(6) Go to a place using coordinates and a map. Find an object with this structure:

((plastic, plastic, plastic),

(metal, metal))

(4) Find a place following directions and using coordinates and a map. Identify an object on a photo which does not exist in reality.

(7) Go to a place using coordinates and a map. Find an object with the same structure as a scene on a photo (people dancing around a maypole).

(2) Find an object on the school yard following written directions and looking up the coordinates of this object on a map.

(1) Go to a place using a photo and coordinates. Find an object on a photo which does not exist at this place.
CT: $17 \%$, A: $21 \%$, AR: $7 \%$, Nav: 24\%, Pat: 59\%, Snap: 3\%, Attract: 2.1, Success: $90 \%$

CT: $16 \%$, A: 8\%, AR: 66\%,

Nav: $13 \%$, Pat: 39\%, Snap: $26 \%$, Attract: 1.9, Success: $100 \%$

CT: $15 \%$, A: $27 \%$, AR: 36\%, Nav: 6\%, Pat: 48\%, Snap: $21 \%$, Attract: 2.4 , Success: $77 \%$

CT: $11 \%$, A: 29\%, AR: 22\%,

Nav: $79 \%$, Pat: $7 \%$, Snap: $11 \%$, Attract: 1.8, Success: 93\%

CT: $3 \%$, A: 23\%, AR: 55\%,

Nav: $20 \%$, Pat: $38 \%$, Snap: $30 \%$ Attract: 2.3, Success: $87 \%$

Ratings show that most students loved the Smartwalk. Participants' statements during the reflection at the end suggest that the experience of success and insight makes a challenge attractive ("I like this task because I was able to understand and to solve it”). In contrast to results of the ROSE study [6], structure-oriented tasks $(3,6)$ were rated as rather attractive.

From a computer scientist's point of view all challenges are related to computer technology (CT) in some way. The challenges listed in Table 1 are ordered according to their overall correspondence to CT from the perspective of the young Smartwalkers. Challenges highly related to CT contained these elements:

- Create something and publish it (10: 42\%, 11: 26\% )

- A tuple, formally describing the structure of a real thing (5: $34 \%, 3: 24 \%$ )

- $\quad$ URL-like addresses (10: 42\%, 9: 35\%)

In some cases the young participants were able to apply the presented CS concepts, when discussing the challenges. They related "Augmented Reality" to challenges that require identifying non-existent objects (4: 66\%, 1: 55\%). Challenges which contained tuples describing real objects were related to pattern recognition (3: 63\%, 6: 59\%, 5: 43\%)

Challenge 8 includes a LOGO-like program that describes the shape of a ventilation pipe. Instead of stating a correspondence with pattern-recognition (13\%) most students related this problem to navigation (78\%). This reflects the intuitive understanding of the LOGO-Turtle commands. Statements like go forward 200 $\mathrm{cm}$ are easy to understand because they are from the knowledge domain of navigation, which is familiar to 12 years old children.

\section{Conclusion}

Outdoor activities on Computer Science - like Smartwalk - help students to get a new perspective on digital devices they use all day. Since the tasks can be designed to be self-contained (no pre-knowledge necessary), they can be integrated in a media 
education curriculum for everybody. Experience-oriented outdoor activities can also be enrichment in a regular computer science class that focuses on programming. Creating programs is a constructive process. The motivation for working on the project is the expectation that we have a nice product at the end. This is the philosophy of Constructionism (Papert, Resnick). Create a digital artifact, share it and discover "big ideas" during the process [12]. An experience-oriented outdoor activity like Smartwalk follows a different approach. The idea is to inspire children to look at the world from a different perspective - the perspective of a computer scientist. Instead of producing (taking the role of an artist or engineer), it is about trying out, reflecting and discussing concepts used in digital technology (taking the role of a philosopher).

\section{References}

1. Medienpädagogischer Forschungsverbund Südwest (2015): KIM-Studie 2014. Stuttgart. Retrieved from:

https://www.mpfs.de/fileadmin/files/Studien/KIM/2014/KIM_Studie_2014.pdf

2. Markowetz, A. (2015) Digitaler Burnout. Knaur Verlag, Munich, Germany.

3. Gallenbacher, J. Abenteuer Informatik. IT zum Anfassen. Spektrum Akademischer Verlag 2006.

4. Bell, T. C., Witten, I. H., \& Fellows, M. R. (1998). Computer Science Unplugged: Off-line activities and games for all ages.

5. Bell, T., Alexander, J., Freeman, I., \& Grimley, M. (2009). Computer science unplugged: School students doing real computing without computers. The New Zealand Journal of Applied Computing and Information Technology, 13(1), 2029.

6. Sjøberg, S., \& Schreiner, C. (2010). The ROSE project: An overview and key findings. Oslo: University of Oslo, 1-31.

7. Ziegenspeck, J.: Erlebnispädagogik: Entwicklungen und Trends. In Spektrum Freizeit, 18,1, (1996), 51 -58.

8. Wing, J. M. (2006. Computational Thinking. Communications of the ACM Vol. 49/ 3 (2006), 33-35

9. Selby, C., \& Woollard, J. (2013). Computational thinking: the developing definition. Retrieved from: https://core.ac.uk/download/pdf/17189251.pdf

10. Torreano, L. A., Cacciari, C. \& Glucksberg, S. (2005). When Dogs Can Fly: Level of Abstraction as a Cue to Metaphorical Use of Verbs. In: METAPHOR AND SYMBOL, 20(4), 259-274

11. Lakoff, G. \& Núnez, R. E.(1997). The Metaphorical Structure of Mathematics: Sketching Out Cognitive Foundations for a Mind-Based Mathematics. In Mathematical Reasoning. Analogies, Metaphors, and Images edited by Lyn D. Lawrence Erlbaum Associates, Publishers, Mahwah, London

12. Papert, S.: Mindstorms (1980): Children, computers, and powerful ideas. Basic Books, Inc. 